\title{
The Kidney from Prenatal to Adult Life: Perinatal Programming and Reduction of Number of Nephrons during Development
}

\author{
Melania Puddu ${ }^{a}$ Vassilios Fanos ${ }^{a}$ Francesca Podda ${ }^{a}$ Marco Zaffanello ${ }^{b}$ \\ ${ }^{a}$ Department of Pediatrics and Clinical Medicine, NICU, University of Cagliari, Cagliari, and ${ }^{\mathrm{b}}$ Department of \\ Mother-Child and Biology-Genetics, University of Verona, Verona, Italy
}

\section{Key Words}

Nephrons, number of · Perinatal programming •

Glomerular hyperfiltration - Intrauterine growth

restriction $\cdot$ Renal volume

\begin{abstract}
Modified embryonic-fetal development resulting in low birth weight may lead to a reduced nephron endowment, hypertension and renal diseases in adulthood. Regarding the involvement of genetic factors, several environmental conditions may also contribute towards reducing the number of nephrons in the fetus and infant, subsequently constituting a health burden in later life. To date no methods of investigation for the early detection of a reduced nephron reserve are available. However, more structured studies should be implemented to investigate the role of angiotensin-converting enzyme inhibitors in managing proteinurias and glomerulosclerosis in children with renal conditions characterized by reduce nephron number and glomerular hypertrophic changes. In view of the current lack of specific methods of investigation and management, close monitoring of children and young adults at risk of reduced renal reserve should be carried out to enhance the early detection of potential changes in renal function.
\end{abstract}

Copyright $\odot 2009$ S. Karger AG, Basel

\section{KARGER}

Fax +4161306 1234 E-Mail karger@karger.ch www.karger.com (c) 2009 S. Karger AG, Basel

0250-8095/09/0302-0162\$26.00/0

Accessible online at:

www.karger.com/ajn

\section{Introduction}

The processes of development and maturation of organs occur continuously throughout the pre- and postnatal periods. Intrauterine growth is generally regulated by intrinsic growth potential, genetic endowment, and support of extrinsic growth provided by nutrients and oxygen from the materno-uteroplacental unit. However, during the postnatal period growth may be affected by environmental conditions and genetic background.

Barker et al. [1,2] and Brenner et al. [3] reported how a modified embryonic-fetal development resulting in low birth weight (LBW) may lead to a reduced nephron endowment, hypertension and renal diseases in adulthood. Regarding the involvement of genetic factors, several environmental conditions may also contribute towards reducing the number of nephrons in the fetus and infant, subsequently constituting a health burden in later life.

\section{Reduction in the Number of Nephrons and Disease}

In humans the overall number of nephrons ranges between 617,000 and 1,075,000 (mean 850,000 nephrons). Variations in nephron number have been associated with different clinical conditions: hypertensive adults have a

V. Fanos, MD

Department of Pediatrics - Neonatal Intensive Care Unit

Puericultura Institute and Neonatal Section

Via Ospedale 119, IT-09124 Cagliari (Italy)

Tel./Fax +39070609 3438, E-Mail vafanos@tin.it 
mean of $\sim 702,000$ nephrons, lower than that displayed by normotensive subjects with a mean of $1,429,000$ [4].

The pathophysiological characteristics of diseases associated with a reduced number of glomeruli are linked to a cascade of events ultimately resulting in compensatory nephron hypertrophy. A low number of nephrons is associated with global renal reduced glomerular volume (although in a single nephron there is a compensatory increase in glomerular volume), reduced surface filtration area, impaired tubular function and changes in vascular permeability.

In the mouse model, the loss of one allele per glial cell line-derived neurotrophic factor (GDNF) resulted in an approximately $30 \%$ reduction in normal sized glomeruli. At a later stage of life the same animals developed high arterial blood pressure featuring glomerular hypertrophy and hyperfiltration of kidneys manifested as a compensatory mechanism for the reduced number of nephrons [5]. In spite of the finding in humans that small for gestational age (SGA) newborns displayed shorter renal length than appropriate for gestational age (AGA), on ageing they manifested either an accelerated renal maturation process or early compensatory kidney hypertrophy [6]. A low nephron endowment led to the onset of compensatory mechanisms in the residual nephrons consisting of glomerular hypertension, high nephron filtration rates, and lastly glomerular hypertrophy [7]. On the basis of the hyperfiltration hypothesis, the larger glomeruli predispose an individual to developing hyperperfusion injury and further deterioration of renal function from increased workload, proteinuria with glomerulosclerosis, tubulointerstitial inflammation and fibrosis $[7,8]$.

The risk factors underlying the onset of hypertension and renal disease are: family history of hypertension and renal disease, diabetes mellitus, obesity, dietary factors, insulin resistance, gestational diabetes, and at-risk ethnic groups. Oligonephronia, whether or not associated with LBW, should be added to a growing list of risk factors of progressive renal disease. Hyperfiltration produced as a result of reduced glomerular number may also be responsible for microalbuminuria, a known early marker for renal disease and hypertension [9]. Moreover, the marked reduction in nephron number characterizing renal hypoplasia/dysplasia leads to a decline in renal function and development of chronic renal failure in childhood [10]. Nevertheless, a small reduction in nephron number in subjects featuring intrauterine growth retardation (IUGR) and LBW has also been associated with renal failure and hypertension in adult life [11].

The Kidney from Prenatal to Adult Life

\section{Causes Underlying a Reduction in Nephron Number}

Perinatal programming controls nephrogenesis during the developmental stage up to 34-36 weeks of gestational age. In infants born before 36 weeks of gestation, nephrogenesis is still ongoing following preterm delivery [12]. Intrauterine stress or prenatal or postnatal perturbation in preterm infants may result in a reduced nephron number. Any adverse event occurring prior to completion of nephrogenesis likely compromises renal growth and produces a longer-lasting effect on final renal potential. However, perinatal programming for hypertension and diabetes may elicit a synergistic impact with the reduced nephron number leading to the development of chronic kidney disease $[12,13]$.

The causes underlying a reduced number of nephrons in an individual are both genetic and environmental. The environmental impact on a genetic program yields the renal perinatal programming of each individual. Furthermore, an ongoing interaction between genes and the environment from prenatal to adult life will contribute towards forming the renal potential of an individual. Signaling molecules and transcription factors have been implicated in determining segmental nephron identity and functional differentiation. While some of these genes (p53 gene family, hepatocyte nuclear factor-1 $\beta$ ) promote the terminal epithelial differentiation fate, others (Notch, Brn-1, IRX, KLF4, and Foxil) regulate the differentiation of specific nephron segments and cellular types $[14,15]$. Congenital oligomeganephronia, clinically characterized by bilateral renal hypoplasia with a reduced number of enlarged nephrons, has been associated with PAX2 gene mutations [16]. Furthermore, the renin-angiotensin system plays a critical role in kidney development. Therefore, angiotensin-converting enzyme (ACE) gene insertion/deletion (I/D) polymorphism does not affect the risk of alterations in renal morphogenesis, but is involved in the physiopathology of disease progression from acquired glomerular disorders to renal hypoplasia, dysplasia, and uropathies [17]. Additionally, genetic issues underlie the development of small, undifferentiated kidneys, nephron hypoplasia, dysplasia and hypodysplasia, in which unknown factors may modify the severity of clinical presentation. Moreover epigenetic changes, characterized by alterations in chromatin structure through modification of histone by methylation, acetylation, phosphorylation and ubiquitylation, lead to stable and potentially hereditable changes in gene expression. In particular, DNA methylation has been strongly implicated in fetal renal development and disease $[18,19]$.

Am J Nephrol 2009;30:162-170 


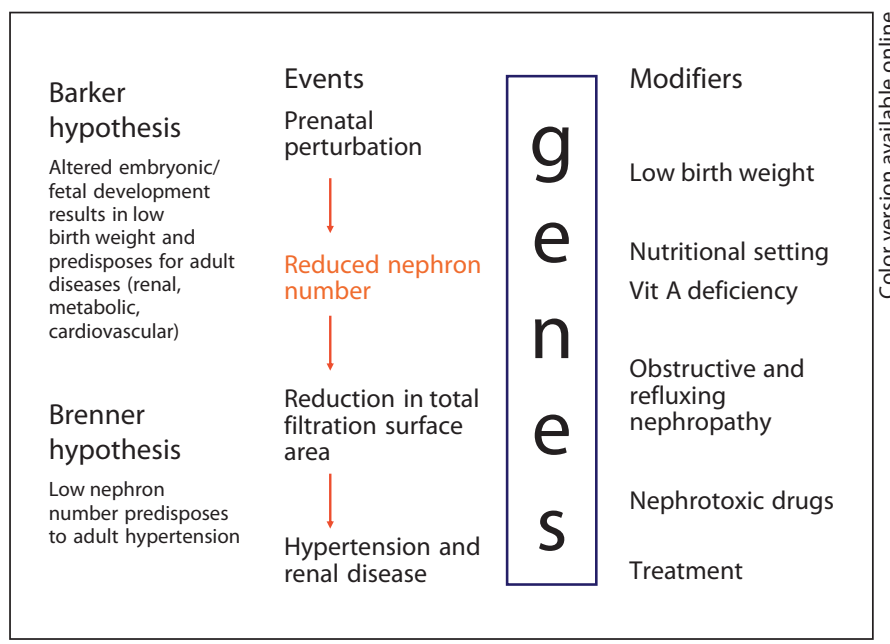

Fig. 1. Environmental stressors and genetic programming of low nephron number.

Accordingly, congenital renal anomalies are more frequent in relatives of patients than in controls. Therefore, variability in the presence, type, unilateral or bilateral involvement of renal malformation may be explained by diverse gene-environmental interactions among individuals of affected families [20].

Several environmental stressors may act on specific genetic programming of low nephron number (fig. 1). Alterations to genetic pattern during fetal development may be produced by nature, timing, duration and severity of the renal insult. In particular, the time at which an adverse factor is involved during gestation before completion of nephrogenesis may affect kidney growth [21]. However, malnutrition caused by a low protein-calorie diet during intrauterine and neonatal life and bad eating habits in later life (excessive salt intake, unbalanced fat and protein in the diet) may have adverse implications on renal outcome $[8,9]$. Moreover, additional stressors affecting renal structure and function are a history of LBW and IUGR, vitamin A deficiency, urinary tract malformations such as obstructive uropathy and infections, administration of nephrotoxic drugs (especially antibiotics and non-steroidal anti-inflammatory drugs, NSAIDs) to mothers and newborns $[22,23]$. All factors may interact to increase potential nephron damage.

\section{$L B W$ and Extreme Prematurity}

LBW represented an independent risk factor for chronic renal injury in experimental studies on rats. Animal kidneys showed reduced glomerular number and high glomerular size [24, 25].
Autopsy studies in newborns and children have reported a marked association between LBW and reduced nephron number [24, 26, 27]. At birth, LBW infants without renal failure displayed a compensatory higher glomerular volume [27-29]. Low glomerular number and high glomerular size have been associated with the development of hypertension, cardiovascular disease and increased susceptibility to renal disease in later life $[21,30$, 31]. Moreover, a study performed in human twins suggested that the association between LBW and renal dysfunction is closely correlated with the involvement of individual fetoplacental factors, whereas genetic factors would appear to be of lesser importance [32]. Poor socioeconomic and nutritional status in the mother may imply a reduced supply of nutrients to the developing fetus. Similarly, factors that hinder the passage of nutrients through the placenta, such as smoking and hypertension, are associated with an increased risk of LBW. Factors affecting intrauterine space availability, such as primiparity, low maternal height, and mothers who were born SGA, are additional risk factors for LBW [33].

The overall prevalence of hypertension in pediatric age is $<1 \%$. Therefore, in the presence of a neonatal history of LBW or prematurity, blood pressure should be strictly monitored during early childhood in view of the risk of hypertension [34]. LBW implied an increased risk of disease in adult life, in particular coronary heart disease, reduced insulin sensitivity and increased blood pressure $[2,35]$. However, very-LBW (VLBW) infants featured a high rate $(10 \%)$ of hypertension after a followup of 6-12 years [36]. Furthermore, preterm children were characterized by a high rate of hypertension (6.8\%), with no differences between AGA and SGA. After 5 years of follow-up, renal risk in children born preterm was similar between AGA and SGA, as well as between VLBW and LBW $[34,37]$.

LBW was associated with hypertension and renal disease in African Americans of southeastern USA [27, 38]. In Australian Aboriginals, LBW disposed to albuminuria and a high rate of early-onset chronic renal failure [39]. LBW and SGA in Aboriginals was more than twice that observed in the general Australian population, with hypertension, cardiovascular disease, and the frequency of albuminuria being twofold the normal rates. However, susceptibility to renal disease was significantly higher than in controls $[40,41]$. Long-term renal follow-up of VLBW infants born without neonatal renal failure revealed a reduction in renal function following reduced nephron endowment [36]. Furthermore, VLBW infants with renal failure showed clear evidence of active glo- 
merulosclerosis in addition to low glomerular supply [29]. Among VLBW children with neonatal acute renal failure, almost half developed chronic renal failure, a minority of which required kidney transplant [42]. Renal damage and hypertension may constitute a risk later in life due to the presence of glomerular stress following nephron hypertrophic changes in individuals born preterm or LBW with neonatal renal complications including renal failure and signs of glomerular and tubular damage.

Microalbuminuria was the most interesting urinary marker of renal outcome in preterm infants. Indeed, the latter showed variable results in line with different study protocols, methods and populations investigated. The prevalence of microalbuminuria measured by means of traditional methods was $11 \%$, affording variable results ranging from 2.7 [43] to $12.5 \%$ [36]. The prevalence of microalbuminuria at young adult age of SGA subjects was 3.8\%, 2.4 times higher than in AGA subjects [43]. On the contrary, no difference was reported for microalbuminuria between AGA and SGA, VLBW and LBW infants and in subjects with normal and high blood pressure [37]. The variability of the results observed, linked possibly to different preterm populations studied, the number of infants and methods of analysis, is somewhat questionable.

Although IUGR was associated with both a low nephron endowment and increased risk of hypertension, only circumstantial evidence obtained in animal studies has been advocated to support the hyperfiltration hypothesis after prenatal programming [44]. Recently, the findings of several human studies did not support the hypothesis that intrauterine growth restriction and prematurity contribute to the alteration of renal function in childhood and young adult life [45, 46].

\section{Nutritional Setting}

Maternal nutrition may have an important influence on renal programming [2]. The majority of studies investigating the relationship between nutrition and nephrogenesis have focused on animal models. In rats, a restricted supply of nutrients to the mother during the critical window in which nephrogenesis occurs led to a reduced number of glomeruli per kidney, activation of the reninangiotensin system, glomerular enlargement, and hypertension in later life [47].

Different nutritional conditions (IUGR, overfeeding and IUGR plus overfeeding) were investigated in 4month-old rats to evaluate the amount of protein urinary excretion as a marker of glomerular damage. Early post- natal overfeeding in rats improved postnatal nephron number. Therefore, enhanced nephron number was associated with elevated arterial pressure and glomerulosclerosis [48].

\section{Vitamin A Deficiency}

Vitamin A is a determinant in fetal renal programming of rats in view of its capacity to closely modulate nephron number and vascular supply. Vitamin A and its analogs (retinoids) are important regulators of cell proliferation, differentiation, immune function and apoptosis [49]. In 21-day-old rats, the number of nephrons was directly correlated with plasma vitamin A. Vitamin A deficiency led to a reduction in nephron number in rats. Under conditions of vitamin A deprivation, proto-oncogene c-ret expression was decreased in metanephron. The role of c-ret in renal formation is considered essential since null mice for these genes exhibited renal agenesis or rudimental kidneys [50]. On the contrary, vitamin A supply restored nephron endowment to normal in offspring of rat mothers exposed to protein restriction [51].

Furthermore, indirect evidence has emphasized the role of vitamin A in kidney development in humans. Vitamin A was seen to be lacking in cord and maternal blood in IUGR neonates. However, low circulating levels were common in women who were smokers, were known to abuse alcohol, or implemented inadequate dietary practices, all situations associated with IUGR delivery [49]. Finally, maternal vitamin A deficiency accounted for subtle renal hypoplasia in Indian newborns [52].

\section{Obstructive and Refluxing Nephropathy}

Obstructive uropathy during the perinatal period may be a leading cause of a reduction in nephron number. Mechanical stretch, implicated in the oncoming nephropathy, leads to tubular responses via the activation of ion channels, increases in intracellular calcium levels and cellular apoptosis [53].

Unilateral obstruction and reduction in the nephron number were investigated in neonatal rat models. Following relief of unilateral urinary obstruction, the ultimate growth of the post-obstructed kidney was impaired, the number of glomeruli reduced, and GFR decreased. The major renal damage observed following unilateral ureteral obstruction was renal tubular apoptosis and atrophy [54]. The opposite kidney showed significant compensatory growth. Moreover, glomerular sclerosis, tubular atrophy, macrophage infiltration, and interstitial fibrosis were significantly increased not only in the post-obstructed kidney, but also in the opposite kidney 
[55-57]. On the contrary, urinary obstruction during adulthood did not elicit a reduction in the number of nephrons. The kidney seems to be vulnerable to urinary tract obstruction both during and immediately following nephrogenesis [56].

In newborns, unilateral obstructed kidney was characterized by a poor outcome even when surgery was performed at an early stage, due to the fact that kidneys continued to develop tubular atrophy and interstitial fibrosis $[58,59]$. The persistently low growth and volume of this unilateral obstructed kidney suggested a reduction in the total nephron number subsequent to apoptosis and/or inhibition of glomerulogenesis. The unobstructed kidney developed a higher volume to compensate for the persistently low function of the affected organ $[60,61]$.

Similar to congenital obstruction, high-grade vesicoureteral reflux leads to poor renal outcome. Vesico-ureteral reflux diagnosed at birth on prenatal ultrasonography was associated with early congenital damage [62]. In particular, refluxing kidneys feature smaller dimensions compared to contralateral non-refluxing organs. Prenatal diagnosis and early treatment did not modify renal outcome, thereby suggesting early fetal damage during nephrogenesis. Renal growth failure seems to correlate with the severity of vesico-ureteral reflux since it worsens in patients with an increased grade of severity [63]. Altered renal programming leading to a reduction in glomerular number or apoptosis should also be taken into account in high-grade vesico-ureteral reflux.

\section{Nephrotoxic Drugs}

Several drugs have been shown to produce an adverse affect on kidneys when administered during pregnancy or in preterm infants when the exposure occurs during active nephrogenesis. In prematurity, shorter nephrogenesis and a reduced number of glomerular layers have been associated with a peculiar magnitude of damage following exposure to nephrotoxic medication [44]. However, mothers of preterm infants developing acute renal failure had invariably taken larger quantities of drugs during pregnancy and delivery, mainly antibiotics and NSAIDs. Furthermore, preterm infants who developed renal failure had unfailingly received more drugs, mainly antibiotics, NSAIDs and diuretics [64].

Several observations on drug-related nephrotoxicity were derived from rat models. $\beta$-Lactam antibiotics (amoxicillin and ampicillin) administered to the rat mother may cross the placenta and reach the fetus. Penicillin given at therapeutic doses produced mild oligonephronia and cystic tubule dilation. Indeed, ceftriaxon at high doses led to impairment of nephrogenesis and blocked kidney development leading to permanent severe renal defects [65]. Aminoglycoside antibiotics given to pregnant females cross the placenta and accumulate in the fetal kidney. Exposure to gentamycin at early stages of gestation lowered the final number of nephrons leading to an increased rate of protein urinary excretion [66, 67]. Following administration of gentamycin in rats, renal changes detected by light and electron microscopy were consistent with significant changes in glomerular and tubular structure [68].

Preterm SGA infants administered aminoglycosides showed impaired glomerular and tubular function to a greater extent than those not receiving the drug [69]. Moreover, following the administration of drugs to the mother or postnatal exposure to exposure, some degree of nephrotoxic action was frequently observed in term newborns. The onset of nephrotoxicity is particularly frequent with specific classes of antibacterial drugs (aminoglycosides and vancomycin), although generally being reversible on discontinuation of the drug $[70,71]$.

The risk of development of acute renal failure in the neonate is high following maternal exposure to NSAIDs. During pregnancy, when nephrogenesis occurs, exposure to NSAIDs may lead to hypoperfusion of the kidneys and long-term renal dysfunction. After long-term in utero exposure, NSAIDs induced nephrotoxicity in the fetus by reducing PGE2 leading to vasomotor nephropathy from renal vasoconstrictions [72]. Indomethacin, in exposed fetuses, led to cystic changes in the developing nephrons [73], and acute/chronic renal failure in newborns or infants born at or before 30 weeks of gestation $[74,75]$. Conversely, the risk of renal impairment is lower, although not null, in newborns exposed in utero to NSAIDs once nephrogenesis has been completed [76]. The nephrotoxic actions of NSAIDs at postnatal ages are produced by ibuprofen leading to acute renal failure in term newborns [75]. Moreover, indomethacin exhibited potent suppressive effects on renal COX-2 and vasodilator prostanoids, important regulators of renal development and function, when administered during early postnatal life [77]. Furthermore, similar to effects described with indomethacin, nimesulide has been associated with maternal oligohydramnios, acute or chronic renal failure in the newborns of treated mothers following in utero exposure lasting from a few days to months. Indeed, some of the above patients manifested transient acute renal failure, prolonged acute renal failure and required peritoneal dialysis [78-81]. 
Adverse effects related to ACE inhibitors have been well documented and include hypotension, oliguria, acute renal failure and hyperkalemia. The major adverse effect is a reduction in glomerular filtration. Particularly bilateral ACE inhibitors should not be administered to patients during pregnancy because human fetopathies have been seen when these drugs were given after the first trimester of pregnancy, the period of fetal kidney development; in particular oligohydramnios, renal tubular dysgenesis and neonatal anuria were observed [82].

Other authors reported adverse fetal and neonatal renal effects after intrauterine exposure to lisinopril, enalapril or other ACE inhibitors. In addition, the ACE inhibitor fetopathy syndrome has been associated with a reduction in amniotic fluid volume as a consequence of the reduced production of fetal urine [83-91].

A study reported by Cooper et al. [92] has shown that almost 9\% of children whose mothers were prescribed ACE inhibitors during the first trimester (but not later) had major congenital anomalies (cardiovascular, central nervous system and renal malformations), a rate 2.7 times that among unexposed infants [92].

Many papers have reported fetal anomalies that are very similar to those produced by maternal treatment with ACE inhibitors, in association with angiotensin II receptor antagonists. Thus, maternal treatment with angiotensin II receptor antagonists should be avoided [93, 94].

\section{Detection of Reduced Nephron Reserve}

Early detection of potential indicators of hyperfiltration, such as impaired renal reserve and blunted solute clearance, may provide subtle clues to the presence of reduced nephron number, increased obsolete glomeruli, thus providing early objective evidence of hypertension, microalbuminurias and renal risks [9]. Since serum CysC levels are frequently superior to serum creatinine levels as an index of renal function [95] with some limitations, it might be introduced as a marker of renal function and follow-up in these patients. Moreover, low renal volume detected by ultrasound measurement of renal length [96, 97] and 3-dimensional ultrasound volume $[98,99]$ might represent suitable parameters of reduced renal reserve in newborns and children. Scintigraphic measurement may provide a comparison of the renal reserve between kidneys and their relative variation by age in congenital unilateral reduced renal reserve [63]. Renal biopsy should only be performed in selected cases and it is not ethically acceptable for wide application.

The Kidney from Prenatal to Adult Life

\section{Treatment}

Several intrauterine risk factors are associated with low nephron number. The early identification of children at higher risk of reduced renal reserve allows consequent monitoring and treatment [22]. However, when possible, the administration of potentially nephrotoxic agents should be carefully evaluated when performed prior to completion of nephrogenesis in the presence of risk factors of reduced renal reserve.

Children with low renal reserve from congenital or acquired renal damage, showing elevated blood pressure or albuminuria, may benefit from prolonged treatment with renal protective agents $[23,100]$. Renoprotective advantages afforded by ACE inhibitors have been demonstrated in animal models, in which angiotensin II played a role in unilateral partial ureteral obstruction regulating glomerular cell apoptosis. Moreover, subsequent to completion of nephrogenesis, angiotensin receptor blockades (ARBs) prevented interstitial and glomerular cell apoptosis in newborn pigs with unilateral ureteral obstruction [101]. Finally, ACE inhibitors decreased interstitial renal fibrosis and preserved renal tubules in newborn dogs with partial urethral obstruction [102].

Having demonstrated effective antiproteinuric and renoprotective actions, today both ACE inhibitors and ARBs are widely used in children to treat numerous chronic renal alterations. Despite different mechanisms of action of these two drugs, they seem to have synergic and adjunctive properties. Accordingly, more structured studies should be implemented to investigate the role of $\mathrm{ACE}$ inhibitors and ARBs in managing proteinurias and glomerulosclerosis in children with renal conditions characterized by reduced nephron number and glomerular hypertrophic changes [79].

However, adverse effects related to ACE inhibitors have been well documented and must be considered in the costs/benefits balance. They include hypotension, oliguria, acute renal failure, and hyperkalemia. The major adverse effect is a reduction in glomerular filtration, particularly in patients with bilateral renal artery stenosis [103].

\section{Conclusion}

Both intrauterine and perinatal events may affect proper long-term renal function, particularly in children at risk of reduced nephron number, such as those born preterm or with LBW. The involvement of stressors dur-

Am J Nephrol 2009;30:162-170 
ing fetal life and active nephrogenesis may lead to reduced nephron generation. However, overall nephron availability constituting the renal potential of an individual is linked to specific genetic background, velocity of nephron loss following a specific insult, age at insult, and duration of the same. Furthermore, the latter lead to reduced renal function altering glomerular structure, eliciting fibrosis and cell apoptosis, and decreasing renal reserve. By responding to the higher requirement of electrolytes and fluid balance per glomerulus, the remaining nephrons will be subjected to hypertrophy and hyperfiltration. Similar conditions are manifested by nephrons in conditions of stress, with modification of local vasoactive conditions resulting in hypertension and proteinuria and, in the long term, cardiovascular diseases and irreversible renal damage. Unfortunately, to date no investigation method for the early detection of reduced nephron reserve is available. Future advances in radiological techniques and biochemical indicators of underlying structural changes in the kidneys may provide important findings. However, in view of the current lack of more specific methods, close monitoring of children and young adults at risk of reduced renal reserve should be carried out to enhance the early detection of potential changes in renal function, paying particular attention to subtle modifications in renal size and volume, and challenges to renal function.

\section{References}

1 Barker DJ, Osmond C, Law CM: The intrauterine and early postnatal origins of cardiovascular disease and chronic bronchitis. J Epidemiol Community Health 1989;43:237240.

-2 Barker DJ, Osmond C, Simmonds SJ, Wield GA: The relation of small head circumference and thinness at birth to death from cardiovascular disease in adult life. BMJ 1993; 306:422-426.

-3 Brenner BM, Garcia DL, Anderson S: Glomeruli and blood pressure: less of one, more of the other? Am J Hypertens 1988;1:335-347.

-4 Keller G, Zimmer G, Mall G, Ritz E, Amann $\mathrm{K}$ : Nephron number in patients with primary hypertension. N Engl J Med 2003;348: 101-108.

5 Cullen-McEwen LA, Kett MM, Dowling J, Anderson WP, Bertram JF: Nephron number, renal function, and arterial pressure in aged GDNF heterozygous mice. Hypertension 2003;41:335-340.

6 Giapros V, Drougia A, Hotoura E, Papadopoulou F, Argyropoulou M, Andronikou S: Kidney growth in small-for-gestational-age infants: evidence of early accelerated renal growth. Nephrol Dial Transplant 2006;21: 3422-3427.

7 Kriz W, LeHir M: Pathways to nephron loss starting from glomerular diseases - insights from animal models. Kidney Int 2005;67: 404-419.

8 Ingelfinger JR: Is microanatomy destiny? $\mathrm{N}$ Engl J Med 2003;348:99-100.

9 Rostand SG: Oligonephronia, primary hypertension and renal disease: 'is the child father to the man?' Nephrol Dial Transplant 2003;18:1434-1438.
10 Woolf AS, Price KL, Scambler PJ, Winyard PJ: Evolving concepts in human renal dysplasia. J Am Soc Nephrol 2004;15:998-1007.

11 Yiu V, Burka S, Zurakowski D, McCormick M, Brenner B, Jabs K: Relationship between birth weight and blood pressure in childhood. Am J Kidney Dis 1999;33:253-260.

12 Ingelfinger JR: Disparities in renal endowment: causes and consequences. Adv Chronic Kidney Dis 2008;15:107-114.

13 Luyckx VA, Brenner BM: Low birth weight, nephron number, and kidney disease. Kidney Int Suppl 2005:S68-S77.

14 El-Dahr SS, Aboudehen K, Saifudeen Z: Transcriptional control of terminal nephron differentiation. Am J Physiol Renal Physio 2008;294:F1273-F1278.

15 Zaffanello M, Brugnara M, Franchini M, Fanos V: TCF2 gene mutation leads to nephrourological defects of unequal severity: an open question. Med Sci Monit 2008; 14: RA78-RA86.

16 Salomon R, Tellier AL, Attie-Bitach T, Amiel J, Vekemans M, Lyonnet S, Dureau P, Niaudet P, Gubler MC, Broyer M: PAX2 mutations in oligomeganephronia. Kidney Int 2001;59:457-462.

-17 Hohenfellner K, Wingen AM, Nauroth O, Wühl E, Mehls O, Schaefer F: Impact of ACE I/D gene polymorphism on congenital renal malformations. Pediatr Nephrol 2001;16: 356-361.

18 Dressler GR: Epigenetics, development, and the kidney. J Am Soc Nephrol 2008;19:2060 2067.

19 Simeoni U, Boubred F, Buffat C, Vaiman D: The developing kidney and the fetal origins of adult cardiovascular disease; in $\mathrm{Oh} \mathrm{W}$, Guignard JP, Baumgart S (eds): Neonatology Questions and Controversies. Nephrology and Fluid/Electrolyte Physiology. Philadelphia, Saunders Elsevier, 2008, pp 97-106.
20 Schwaderer AL, Bates CM, McHugh KM, McBride KL: Renal anomalies in family members of infants with bilateral renal agenesis/adysplasia. Pediatr Nephrol 2007;22:5256.

21 Hotoura E, Argyropoulou M, Papadopoulou F, Giapros V, Drougia A, Nikolopoulos P, Andronikou S: Kidney development in the first year of life in small-for-gestationalage preterm infants. Pediatr Radiol 2005;35: 991-994.

-22 Amann K, Plank C, Dötsch J: Low nephron number - a new cardiovascular risk factor in children? Pediatr Nephrol 2004;19:13191323.

23 Hoy WE, Hughson MD, Bertram JF, Douglas-Denton R, Amann K: Nephron number, hypertension, renal disease, and renal failure. J Am Soc Nephrol 2005;16:2557-2564.

24 Merlet-Bénichou C, Vilar J, Lelievre-Pegorier M, Moreau E, Gilbert T: Fetal nephron mass: its control and deficit. Adv Nephrol Necker Hosp 1997;26:19-45.

25 Merlet-Bénichou C, Gilbert T, Vilar J, Moreau E, Freund N, Lelièvre-Pégorier M: Nephron number: variability is the rule. Causes and consequences. Lab Invest 1999; 79:515-527.

26 Hinchliffe SA, Lynch MR, Sargent PH, Howard CV, Van Velzen D: The effect of intrauterine growth retardation on the development of renal nephrons. Br J Obstet Gynaecol 1992;99:296-301.

$>27$ Hughson M, Farris AB 3rd, Douglas-Denton R, Hoy WE, Bertram JF: Glomerular number and size in autopsy kidneys: the relationship to birth weight. Kidney Int 2003;63:21132122 
28 Mañalich R, Reyes L, Herrera M, Melendi C, Fundora I: Relationship between weight at birth and the number and size of renal glomeruli in humans: a histomorphometric study. Kidney Int 2000;58:770-773.

29 Rodríguez MM, Gómez AH, Abitbol CL, Chandar JJ, Duara S, Zilleruelo GE: Histomorphometric analysis of postnatal glomerulogenesis in extremely preterm infants. Pediatr Dev Pathol 2004;7:17-25.

30 Huxley RR, Shiell AW, Law CM: The role of size at birth and postnatal catch-up growth in determining systolic blood pressure: a systematic review of the literature. J Hypertens 2000;18:815-831.

-31 Zandi-Nejad K, Luyckx VA, Brenner BM: Adult hypertension and kidney disease: the role of fetal programming. Hypertension 2006;47:502-508.

- 32 Gielen M, Pinto-Sietsma SJ, Zeegers MP, Loos RJ, Fagard R, de Leeuw PW, Beunen G, Derom C, Vlietinck R: Birth weight and creatinine clearance in young adult twins: influence of genetic, prenatal, and maternal factors. J Am Soc Nephrol 2005; 16:24712476.

- 33 Hershkovitz D, Burbea Z, Skorecki K, Brenner BM: Fetal programming of adult kidney disease: cellular and molecular mechanisms. Clin J Am Soc Nephrol 2007;2:334342.

- 34 National High Blood Pressure Education Program Working Group on High Blood Pressure in Children and Adolescents: The fourth report on the diagnosis, evaluation, and treatment of high blood pressure in children and adolescents. Pediatrics 2004;114: 555-576.

- 35 Rotteveel J, van Weissenbruch MM, Twisk JW, Delemarre-Van de Waal HA: Infant and childhood growth patterns, insulin sensitivity, and blood pressure in prematurely born young adults. Pediatrics 2008;122:313-321.

- 36 Rodríguez-Soriano J, Aguirre M, Oliveros R, Vallo A: Long-term renal follow-up of extremely low birth weight infants. Pediatr Nephrol 2005;20:579-584.

- 37 Puddu M, Podda MF, Mussap M, Tumbarello R, Fanos V: Early detection of microalbuminuria and hypertension in children of very low birthweight. J Matern Fetal Neonatal Med 2009;22:83-88.

- 38 Lackland DT, Bendall HE, Osmond C, Egan BM, Barker DJ: Low birth weights contribute to high rates of early-onset chronic renal failure in the southeastern United States. Arch Intern Med 2000;160:1472-1476.

- 39 Hoy WE, Rees M, Kile E, Mathews JD, Wang Z: A new dimension to the Barker hypothesis: low birthweight and susceptibility to renal disease. Kidney Int 1999;56:1072-1077.

-40 Spencer J, Wang Z, Hoy W: Low birth weight and reduced renal volume in Aboriginal children. Am J Kidney Dis 2001;37:915920 .
1 Singh GR, Hoy WE: The association between birthweight and current blood pressure: a cross-sectional study in an Australian Aboriginal community. Med J Aust 2003;179: 532-535.

42 Abitbol CL, Bauer CR, Montané B, Chandar J, Duara S, Zilleruelo G: Long-term followup of extremely low birth weight infants with neonatal renal failure. Pediatr Nephrol 2003; 18:887-893.

43 Keijzer-Veen MG, Schrevel M, Finken MJ, Dekker FW, Nauta J, Hille ET, Frölich M, van der Heijden BJ; Dutch POPS-19 Collaborative Study Group: Microalbuminuria and lower glomerular filtration rate at young adult age in subjects born very premature and after intrauterine growth retardation. J Am Soc Nephrol 2005;16:2762-2768.

44 Schreuder MF: Prenatal programming of nephron number and blood pressure. Kidney Int 2007;72:265-268.

-45 Keijzer-Veen MG, Kleinveld HA, Lequin $\mathrm{MH}$, Dekker FW, Nauta J, de Rijke YB, van der Heijden BJ: Renal function and size at young adult age after intrauterine growth restriction and very premature birth. Am J Kidney Dis 2007;50:542-551.

46 Rakow A, Johansson S, Legnevall L, Sevastik R, Celsi G, Norman M, Vanpée M: Renal volume and function in school-age children born preterm or small for gestational age. Pediatr Nephrol 2008;23:1309-1315.

47 Woods LL, Ingelfinger JR, Nyengaard JR, Rasch R: Maternal protein restriction suppresses the newborn renin-angiotensin system and programs adult hypertension in rats. Pediatr Res 2001;49:460-467.

48 Boubred F, Buffat C, Feuerstein JM, Daniel L, Tsimaratos M, Oliver C, Lelièvre-Pégorier M, Simeoni U: Effects of early postnatal hypernutrition on nephron number and longterm renal function and structure in rats. Am J Physiol Renal Physiol 2007;293:F1944F1949.

49 Bhat PV, Manolescu DC: Role of vitamin A in determining nephron mass and possible relationship to hypertension. J Nutr 2008; 138:1407-1410.

50 Lelièvre-Pégorier M, Vilar J, Ferrier ML, Moreau E, Freund N, Gilbert T, Merlet-Bénichou C: Mild vitamin A deficiency leads to inborn nephron deficit in the rat. Kidney Int 1998;54:1455-1462.

51 Makrakis J, Zimanyi MA, Black MJ: Retinoic acid enhances nephron endowment in rats exposed to maternal protein restriction. $\mathrm{Pe}$ diatr Nephrol 2007;22:1861-1867.

52 Goodyer P, Kurpad A, Rekha S, Muthayya S, Dwarkanath P, Iyengar A, Philip B, Mhaskar A, Benjamin A, Maharaj S, Laforte D, Raju C, Phadke K: Effects of maternal vitamin A status on kidney development: a pilot study. Pediatr Nephrol 2007;22:209-214.
53 Quinlan MR, Docherty NG, Watson RW, Fitzpatrick JM: Exploring mechanisms involved in renal tubular sensing of mechanical stretch following ureteric obstruction. Am J Physiol Renal Physiol 2008;295:F1F11.

54 Chevalier RL: Pathogenesis of renal injury in obstructive uropathy. Curr Opin Pediatr 2006;18:153-160.

-55 Chevalier RL, Thornhill BA, Chang AY: Unilateral ureteral obstruction in neonatal rats leads to renal insufficiency in adulthood. Kidney Int 2000;58:1987-1995.

-56 Chevalier RL, Thornhill BA, Chang AY, Cachat F, Lackey A: Recovery from release of ureteral obstruction in the rat: relationship to nephrogenesis. Kidney Int 2002;61:20332043

- 57 Thornhill BA, Burt LE, Chen C, Forbes MS, Chevalier RL: Variable chronic partial ureteral obstruction in the neonatal rat: a new model of ureteropelvic junction obstruction. Kidney Int 2005;67:42-52.

-58 Stock JA, Krous HF, Heffernan J, Packer M, Kaplan GW: Correlation of renal biopsy and radionuclide renal scan differential function in patients with unilateral ureteropelvic junction obstruction. J Urol 1995; 154:716718.

59 Murer L, Benetti E, Centi S, Della Vella M, Artifoni L, Capizzi A, Zucchetta P, Del Prete D, Carasi C, Montini G, Rigamonti W, Zaccello G: Clinical and molecular markers of chronic interstitial nephropathy in congenital unilateral ureteropelvic junction obstruction. J Urol 2006;176:2668-2673.

60 Boubaker A, Meyrat B, Frey P, Bischof Delaloye A: Unilateral urinary flow impairment at the pelviureteral junction: outcome of renal function with respect to therapeutic strategy. Urology 2003;61:1224-1228.

-61 Zaffanello M, Cecchetto M, Brugnara M, Martone E, Zuffante M, Fedrizzi M, Fanos V: Pelvi-ureteric junction obstruction and renal function after pyeloplasty: a retrospective study in 29 children. Minerva Urol Nefrol 2008;60:1-6.

62 Assael BM, Guez S, Marra G, Secco E, Manzoni G, Bosio M, Pelegatta A, Acerbi L, delli Agnola CA, Selvaggio G, Vegni M, Cecchetti V, Cucchi L: Congenital reflux nephropathy: a follow-up of 108 cases diagnosed perinatally. Br J Urol 1998;82:252-257.

-63 Zaffanello M, Brugnara M, Cecchetto M, Fedrizzi M, Fanos V: Renal involvement in children with vesicoureteral reflux: are prenatal detection and surgical approaches preventive? Scand J Urol Nephrol 2008;42:330336.

64 Cataldi L, Leone R, Moretti U, De Mitri B, Fanos V, Ruggeri L, Sabatino G, Torcasio F, Zanardo V, Attardo G, Riccobene F, Martano C, Benini D, Cuzzolin L: Potential risk factors for the development of acute renal failure in preterm newborn infants: a casecontrol study. Arch Dis Child Fetal Neonatal Ed 2005;90:F514-F519. 
65 Nathanson S, Moreau E, Merlet-Benichou C, Gilbert T: In utero and in vitro exposure to beta-lactams impair kidney development in the rat. J Am Soc Nephrol 2000;11:874-884.

- 66 Gilbert T, Gaonach S, Moreau E, MerletBenichou C: Defect of nephrogenesis induced by gentamicin in rat metanephric organ culture. Lab Invest 1994;70:656-666.

-67 Smaoui H, Schaeverbeke M, Mallié JP, Schaeverbeke J: Transplacental effects of gentamicin on endocytosis in rat renal proximal tubule cells. Pediatr Nephrol 1994;8:447-450.

68 Kent AL, Maxwell LE, Koina ME, Falk MC, Willenborg D, Dahlstrom JE: Renal glomeruli and tubular injury following indomethacin, ibuprofen, and gentamicin exposure in a neonatal rat model. Pediatr Res 2007;62:307312.

-69 Giapros V, Papadimitriou P, Challa A, Andronikou S: The effect of intrauterine growth retardation on renal function in the first two months of life. Nephrol Dial Transplant 2007;22:96-103.

70 Fanos V, Cataldi L: Antibacterial-induced nephrotoxicity in the newborn. Drug Saf 1999;20:245-267.

-71 Fanos V, Cuzzolin L, Atzei A, Testa M: Antibiotics and antifungals in neonatal intensive care units: a review. J Chemother 2007;19: 5-20.

72 Cuzzolin L, Dal Cerè M, Fanos V: NSAIDinduced nephrotoxicity from the fetus to the child. Drug Saf 2001;24:9-18.

-73 van der Heijden BJ, Carlus C, Narcy F, Bavoux F, Delezoide AL, Gubler MC: Persistent anuria, neonatal death, and renal microcystic lesions after prenatal exposure to indomethacin. Am J Obstet Gynecol 1994;171: 617-623.

-74 Norton ME, Merrill J, Cooper BA, Kuller JA, Clyman RI: Neonatal complications after the administration of indomethacin for preterm labor. N Engl J Med 1993;329:1602-1607.

-75 Kaplan BS, Restaino I, Raval DS, Gottlieb $\mathrm{RP}$, Bernstein J: Renal failure in the neonate associated with in utero exposure to nonsteroidal anti-inflammatory agents. Pediatr Nephrol 1994;8:700-704.

-76 Cuzzolin L, Fanos V, Pinna B, di Marzio M, Perin M, Tramontozzi P, Tonetto P, Cataldi $\mathrm{L}$ : Postnatal renal function in preterm newborns: a role of diseases, drugs and therapeutic interventions. Pediatr Nephrol 2006;21: 931-938.

-77 Hasan J, Beharry KD, Gharraee Z, Stavitsky Y, Abad-Santos P, Abad-Santos M, Aranda JV, Modanlou HD: Early postnatal ibuprofen and indomethacin effects in suckling and weanling rat kidneys. Prostaglandins Other Lipid Mediat 2008;85:81-88.

-78 Landau D, Shelef I, Polacheck H, Marks K, Holcberg G: Perinatal vasoconstrictive renal insufficiency associated with maternal nimesulide use. Am J Perinatol 1999;16:441444.
79 Peruzzi L, Gianoglio B, Porcellini MG, Coppo R: Neonatal end-stage renal failure associated with maternal ingestion of cyclo-oxygenase-type-1 selective inhibitor nimesulide as tocolytic. Lancet 1999;354:1615.

80 Benini D, Fanos V, Cuzzolin L, Tatò L: In utero exposure to nonsteroidal anti-inflammatory drugs: neonatal renal failure. Pediatr Nephrol 2004;19:232-234.

81 Boubred F, Vendemmia M, Garcia-Meric P, Buffat C, Millet V, Simeoni U: Effects of maternally administered drugs on the fetal and neonatal kidney. Drug Saf 2006;29:397-419.

82 Buttar HS: An overview of the influence of ACE inhibitors on fetal-placental circulation and perinatal development. Mol Cell Biochem 1997;176:61-71.

83 Schubiger G, Flury G: Enalapril for pregnancy-induced hypertension: acute renal failure in a neonate. Ann Intern Med 1988;108:215216.

84 Rosa F, Bosco L, Fossum C: Neonatal anuria with maternal angiotensin-converting enzyme inhibition. Obstet Gynecol 1989;74: 371-374

85 Cunniff C, Jones KL, Phillipson J: Oligohydramnios sequence and renal tubular malformation associated with maternal enalapril use. Am J Obstet Gynecol 1990;162: 187-189.

86 Bhatt-Mehta V, Deluga KS: Fetal exposure to lisinopril: neonatal manifestations and management. Pharmacotherapy 1993; 13: 515-518.

87 Shatan A, Widerhorn J, Hurst A: Risk of angiotensin-converting enzyme inhibition during pregnancy: experimental and clinical evidence, potential mechanisms, and recommendations for use. Am J Med 1994;96:451456.

88 Filler G, Wong H, Condello AS, Charbonneau C, Sinclair B, Kovesi T, Hutchison J: Early diagnosis in a neonate with intrauterine lisinopril exposure. Arch Dis Child Fetal Neonatal Ed 2003;88:F154-F156.

89 Murki S, Kumar P, Dutta S, Narang A: Fatal neonatal renal failure due to maternal enalapril ingestion. Matern Fetal Neonatal Med 2005; 17:235-237.

90 Tabacova S, Little R, Tsong Y, Vega A, Kimmel CA: Adverse pregnancy outcomes associated with maternal enalapril antihypertensive treatment. Pharmacoepidemiol Drug Saf 2003;12:633-646.

-91 Shrim A, Berger H, Kingdom J, Hamoudi A, Shah PS, Koren G: Prolonged exposure to angiotensin-converting enzyme inhibitors during pregnancy. Fetal toxicity could be reversible. Can Fam Physician 2005;51:13351337
\$2 Cooper WO, Hernandez-Diaz S, Arbogast PG, Dudley JA, Dyer S, Gideon PS, Hall K, Ray WA: Major congenital malformations after first-trimester exposure to ACE inhibitors. N Engl J Med 2006;354:24432451.

-93 Lambot MA, Vermeylen D, Noël JC: Angiotensin-II-receptor inhibitors in pregnancy. Lancet 2001;357:1619-1620.

94 Alwan S, Polifka JE, Friedman JM: Angiotensin II receptor antagonist treatment during pregnancy. Birth Defects Res A Clin Mol Teratol 2005;73:123-130.

95 Zaffanello M, Franchini M, Fanos V: Is serum cystatin-C a suitable marker of renal function in children? Ann Clin Lab Sci 2007;37:233-240.

$\$ 96$ Safak AA, Simsek E, Bahcebasi T: Sonographic assessment of the normal limits and percentile curves of liver, spleen, and kidney dimensions in healthy school-aged children. J Ultrasound Med 2005;24:13591364.

97 Vujic A, Kosutic J, Bogdanovic R, Prijic S, Milicic B, Igrutinovic Z: Sonographic assessment of normal kidney dimensions in the first year of life - a study of 992 healthy infants. Pediatr Nephrol 2007;22:11431150.

98 Riccabona M, Fritz G, Schollnast H, Schwarz T, Deutschmann MJ, Mache CJ: Hydronephrotic kidney: pediatric threedimensional US for relative renal size assessment - initial experience. Radiology 2005;236:276-283.

99 Kim HC, Yang DM, Lee SH, Cho YD: Usefulness of renal volume measurements obtained by a 3-dimensional sonographic transducer with matrix electronic arrays. J Ultrasound Med 2008;27:1673-1681.

100 Zaffanello M, Franchini M, Fanos V: New therapeutic strategies with combined renin-angiotensin system inhibitors for pediatric nephropathy. Pharmacotherapy 2008; 28:125-130.

101 Eskild-Jensen A, Paulsen LF, Wogensen L, Olesen P, Pedersen L, Frøkiaer J, Nyengaard JR: AT1 receptor blockade prevents interstitial and glomerular apoptosis but not fibrosis in pigs with neonatal induced partial unilateral ureteral obstruction. Am J Physiol Renal Physiol 2007;292:F1771-F1781.

102 Shirazi M, Noorafshan A, Bahri MA, Tanideh N: Captopril reduces interstitial renal fibrosis and preserves more normal renal tubules in neonatal dogs with partial urethral obstruction: a preliminary study. Urol Int 2007;78:173-177.

103 Fanos V, Cuzzolin L: Causes and manifestation of nephrotoxicity; in Geary DF, Shaefer F (eds): Comprehensive Pediatric Nephrology. Philadelphia, Mosby Elsevier, 2008, pp 1003-1006. 